\title{
Surgical options for proximal and distal transverse arch hypoplasia in infants with coarctation
}

\author{
Cong $\mathrm{Li}^{1 \#}$, Jidan $\mathrm{Ma}^{2 \#}$, Yichen Yan ${ }^{1}$, Hongtong Chen ${ }^{1}$, Guocheng Shi ${ }^{1}$, Huiwen Chen ${ }^{1}$, Zhongqun Zhu ${ }^{1}$ \\ ${ }^{1}$ Department of Cardiothoracic Surgery, Shanghai Children's Medical Center, School of Medicine, Shanghai Jiao Tong University, Shanghai, China; \\ ${ }^{2}$ Department of Pediatric Cardiology, Shanghai Children's Medical Center, School of Medicine, Shanghai Jiao Tong University, Shanghai, China \\ Contributions: (I) Conception and design: C Li, J Ma, Y Yan, H Chen, Z Zhu; (II) Administrative support: None; (III) Provision of study materials or \\ patients: Z Zhu, H Chen, J Ma; (IV) Collection and assembly of data: C Li, J Ma, H Chen, G Shi; (V) Data analysis and interpretation: C Li, Y Yan, \\ G Shi, H Chen, Z Zhu; (VI) Manuscript writing: All authors; (VII) Final approval of manuscript: All authors. \\ "These authors contributed equally to this work and should be considered as co-first authors. \\ Correspondence to: Zhongqun Zhu. Department of Cardiothoracic Surgery, Shanghai Children's Medical Center, School of Medicine, Shanghai Jiao \\ Tong University, Shanghai 200127, China. Email: zhuzhongqun@scmc.com.cn.
}

Background: Although various surgical techniques have been reported for aortic arch reconstruction for proximal and distal transverse arch (PDTA) hypoplasia, no consensus has been reached on a surgical option for initial arch reconstruction. This study was undertaken to review various arch reconstruction options for PDTA hypoplasia in Chinese infants.

Methods: A retrospective review of 121 infants who underwent initial arch reconstruction of the proximal and distal aortic arches between 2010 and 2020 was performed. Freedom from recoarctation was analyzed using Kaplan-Meier analysis. Univariate and multivariable Cox regression analyses were performed to determine perioperative data associated with an increased risk of recoarctation after surgery.

Results: Aortic arch reconstruction was performed by end-to-side anastomosis (ESA) $(\mathrm{n}=37)$ or patch repair [autologous pericardial patch (APP), $n=53$; bovine pericardial patch (BPP), $n=20$; autologous pulmonary artery patch (APAP), $\mathrm{n}=11$ ]. The relative diameter of the proximal arch was $0.51 \pm 0.07$, and the relative diameter of the distal arch was $0.43 \pm 0.07$. The median follow-up time was 679 (range, 388-1,362) days. Recoarctation was observed in $44(36.4 \%)$ patients. ESA was an independent risk factor for further development of recoarctation after the initial aortic arch reconstruction [hazard ratio $(\mathrm{HR})=2.13 ; \mathrm{P}=0.020$ ].

Conclusions: Aortic arch reconstruction via ESA was an independent risk factor for late recoarctation of the proximal and distal aortic arches in patients who underwent the initial surgery in infancy.

Trial Registration: Chinese Clinical Trials Registry ChiCTR2100048212.

Keywords: Transverse arch hypoplasia; aortic arch; arch reconstruction; coarctation; congenital heart disease

Submitted Nov 29, 2021. Accepted for publication Jan 18, 2022.

doi: $10.21037 / \mathrm{tp}-21-557$

View this article at: https://dx.doi.org/10.21037/tp-21-557

\section{Introduction}

The transverse aortic arch can be divided into two parts: the proximal and distal arches. The use of extended end-to-end repair in patients with distal arch hypoplasia is associated with safe and excellent results (1). However, the surgical option for proximal and distal transverse arch (PDTA) hypoplasia is controversial. Several surgical techniques have been reported to repair the PDTA: (I) direct anastomosis, including end-to-side anastomosis (ESA) or extended endto-end anastomosis (EAAA); (II) patch aortoplasty, including autologous pericardial patch (APP), bovine pericardial patch (BPP), and autologous pulmonary artery patch (APAP). However, no consensus has been reached on the surgical option for PDTA hypoplasia. Direct anastomosis has the advantages of few surgical procedures and shorter operative 

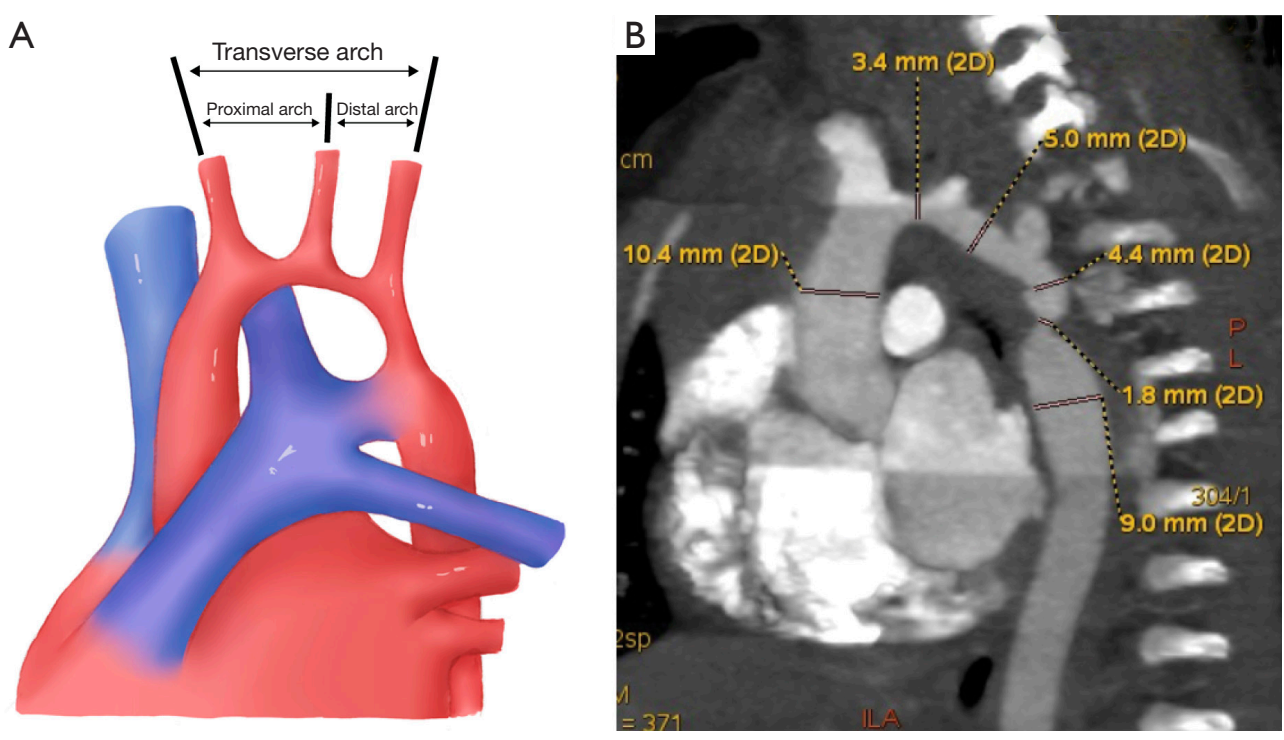

Figure 1 PDTA. (A) Morphology and anatomy (B) computed tomography image. PDTA, proximal and distal transverse arch.

time, but the changed arch geometry may more likely cause recoarctation or hypertension (2). Patch aortoplasty could maintain the arch geometry and decrease the anastomotic tension, but the heterogeneous artery wall may give rise to the formation of an aneurysm $(3,4)$.

Among various surgical options, it is crucial to select the optimal initial surgical approach according to the patients' pathophysiological conditions, especially in infants $(3,5)$. Herein, we describe our single-center experience of various surgical options for PDTA reconstruction. We analyzed the outcomes of different techniques to determine the appropriate surgical option for Chinese infants with PDTA hypoplasia. We present the following article in accordance with the STROBE reporting checklist (available at https:// tp.amegroups.com/article/view/10.21037/tp-21-557/rc).

\section{Methods}

\section{Ethical statement}

The study was conducted in accordance with the principles of the Declaration of Helsinki (as revised in 2013) and approved by the Ethics Committee of Shanghai Children's Medical Center (No. SCMCIRB-W2021038). The requirement for obtaining individual consent for this retrospective analysis was waived. This study has been registered with the Chinese Clinical Trials Registry (https:// www.chictr.org.cn) as ChiCTR2100048212.

\section{Definitions}

The transverse arch is commonly separated into two segments: (I) proximal, between the innominate artery and left common carotid artery, and (II) distal, between the left common carotid artery and the left subclavian artery (Figure 1A).

Both PDTAs are hypoplastic if (I) the ratio of the external diameter of the proximal arch to the ascending aorta ratio is $<0.6$ and the ratio of the external diameter of the distal arch to the ascending aorta ratio is $<0.5$, and (II) its length exceeds $5 \mathrm{~mm}(3,6)$. In this study, a blinded researcher assessed different types of arch hypoplasia using preoperative computed tomography images (Figure 1B). Z-Score was calculated as reported by transthoracic echocardiography (7).

Recoarctation was defined as a pressure gradient across the repair site of $\geq 20 \mathrm{mmHg}$ by transthoracic echocardiography (8).

\section{Patient population and data collection}

Between 2010 and 2020, 857 consecutive patients mainly diagnosed with coarctation or hypoplastic aortic arch were retrospectively identified from the hospital database in Shanghai Children's Medical Center. The inclusion criteria were: (I) diagnosis with PDTA hypoplasia; (II) age at surgery less than 1 year; (III) the operation performed as 


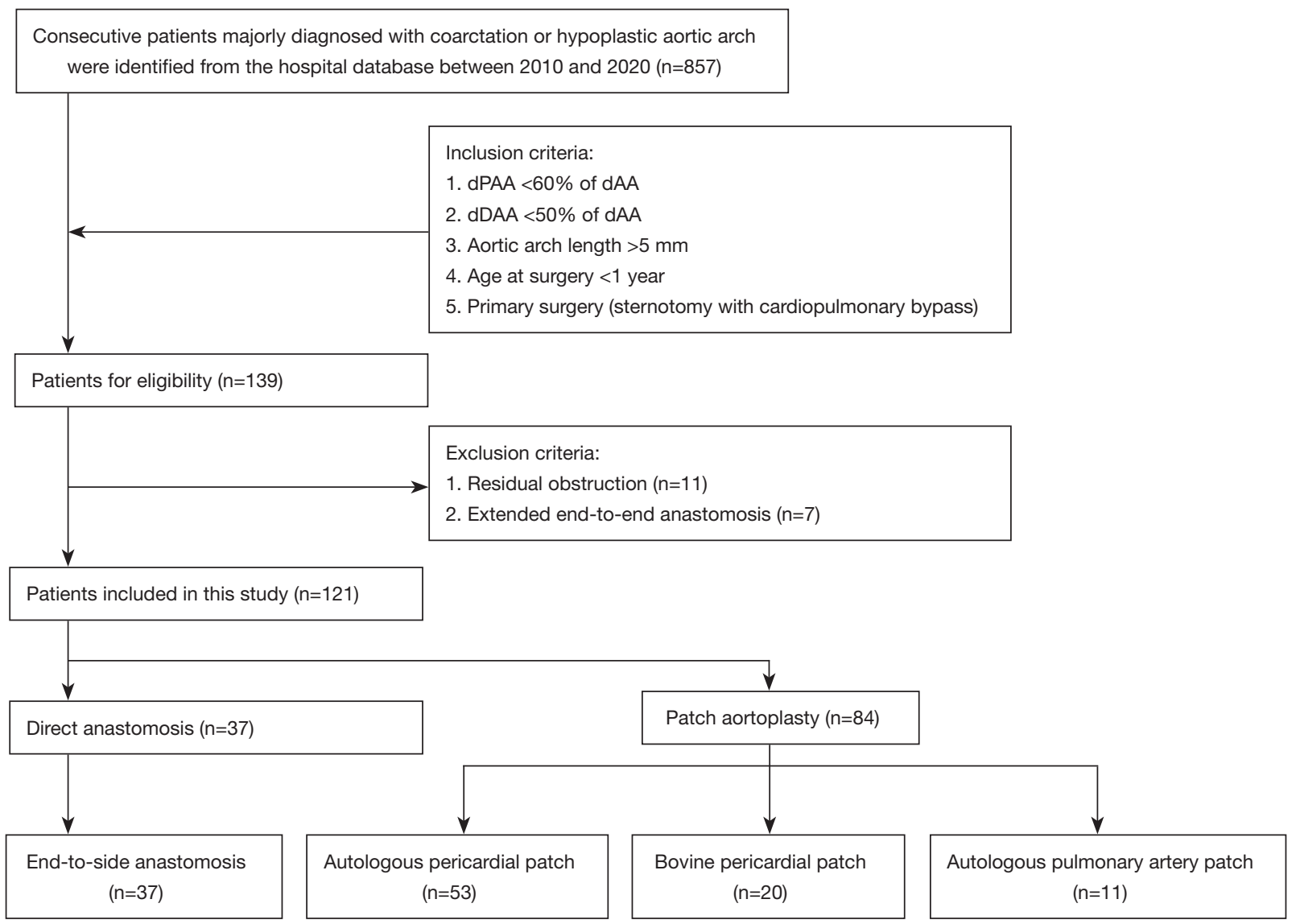

Figure 2 Flow chart of patient selection. dPAA, diameter of the proximal aortic arch; dAA, diameter of the ascending aorta; dDAA, diameter of the distal aortic arch.

primary surgery and via sternotomy with cardiopulmonary bypass. The exclusion criteria were residual obstruction and patients who received EAAA (Figure 2).

After the screening, a total of 121 patients were enrolled. Preoperative, intraoperative, and postoperative data were collected from the patients' inpatient medical records. Follow-ups were scheduled 1,3 , and 6 months after discharge, then every 6 months for the next 18 months, and then regularly once every year. Follow-up data were collected from the outpatient system and telephone calls.

\section{Surgical techniques}

All patients underwent midline sternotomy and cardiopulmonary bypass. Regional cerebral oxygen saturation was monitored using near-infrared spectroscopy in all patients. After cardiopulmonary bypass was initiated, the transverse arch, innominate, left common carotid and left subclavian arteries, isthmus, and descending aorta were exposed and mobilized carefully and widely.

Based on our center experience, the limited ability to tolerate surgery in infants is important, and we would choose ESA due to its fewer procedures and shorter operative time. However, if mobilization of the descending aorta was limited or the aortic arch geometry appeared abnormal, we would change to aorta enlargement by patch repair. In this study, all valves regurgitation were no need for additional surgery. The other additional intracardiac malformations were corrected at one stage.

Reconstruction of the aortic arch was performed according to the following procedures. For the end-to-side procedure, the distance between the ascending aorta and the coarctation was not quite long; hence, it was possible to fully mobilize the descending aorta and directly anastomose it to the terminal end of the ascending aorta, as the proximal descending aorta was ligated. 


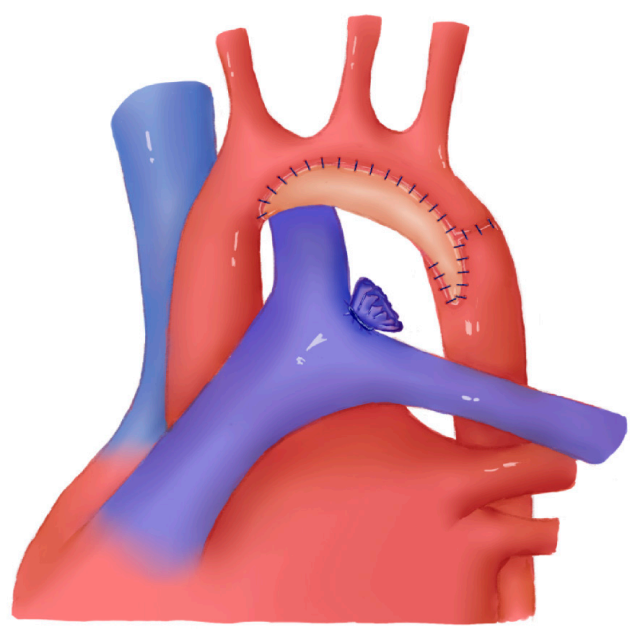

Figure 3 Patch aortoplasty in proximal and distal transverse arch hypoplasia.

In cases of patch aortoplasty, some procedures should be performed before patch use. The dissected autologous pericardium was treated with glutaraldehyde for $10 \mathrm{~min}$ before use. The bovine pericardium was pretreated with glutaraldehyde and used after rinsing it with saline. Pulmonary artery patches were harvested from the main pulmonary artery (MPA). When a pulmonary autograft was used, the remaining defect was repaired with a glutaraldehyde-fixed autologous pericardium or bovine pericardium. Afterward, an incision was made along the inferior aspect of the aortic arch, usually between the innominate artery and descending aorta. When posterior anastomosis was completed, the remaining anterior aspect of the aorta was supplemented with three different patch materials (Figure 3).

For patch material selection, we tended to choose autologous pericardium to perform the arch reconstruction. If the size of autologous pericardium was not large enough to reconstruct the transverse arch, bovine pericardium would be chosen. In some cases whose pulmonary arteries were large enough, pulmonary artery patch would be used to reconstruct aortic arch.

\section{Statistical analyses}

Continuous variables are presented as means \pm standard deviations for normally distributed values or as medians with interquartile ranges (IQRs) for non-normally distributed values. The chi-square or Fisher exact test was used to analyze categorical data. For continuous variables, the Student $t$-test for normally distributed values or MannWhitney $U$ test for non-normally distributed values was used to compare data between two groups. For multiple group comparisons, one-way analysis of variance or Kruskal-Wallis nonparametric tests were used. Freedom from recoarctation was determined as time-to-events using the Kaplan-Meier curve and compared using the two-sided $\log$-rank test. Variables with a $\mathrm{P}$ value $<0.1$ in the univariate analysis were analyzed in a subsequent multivariable model. $P$ values $<0.05$ were considered statistically significant. All statistical analyses were performed using the GraphPad Prism software (version 8.0; GraphPad Software, Inc., La Jolla, CA, USA) or SPSS software (version 26.0; IBM Corp., Armonk, NY, USA).

\section{Results}

\section{Patient characteristics}

Figure 2 shows the flow chart of patient selection and enrollment criteria. Between 2010 and 2020, 857 patients were identified from the hospital database. Moreover, 18 of the 139 patients were excluded from this retrospective review because of residual obstruction or a limited number of patients received EAAA. Finally, we collected data from $121(14.1 \%)$ infants using outpatient and inpatient medical records or telephone calls.

According to the different repair techniques, all 121 patients were divided into four groups: the ESA $(n=37$, $30.6 \%), \operatorname{APP}(n=53,43.8 \%)$, BPP $(n=20,16.5 \%)$, and APAP $(\mathrm{n}=11,9.1 \%)$ groups. Perioperative characteristics are presented in Table 1. Preoperative baseline characteristics were not significantly different between the four groups.

Furthermore, 22 of 121 patients underwent surgery for deep hypothermic circulatory arrest (DHCA), 9 of 128 patients underwent surgery with deep hypothermic low flow (DHLF), and 35 of 128 patients underwent surgery with selective antegrade cerebral perfusion (SACP). In the patch group, APPs ( $n=53)$, BPPs $(n=20)$, and APAPs $(n=11)$ were used to reconstruct the aorta. The mean follow-up time was 1,042 days, and the median follow-up time was 679 (IQR, 388-1,362) days.

\section{Intraoperative and postoperative outcomes}

In terms of intraoperative clinical characteristics, patients in the ESA group presented a shorter aortic cross-clamp time than those in the APP group $(\mathrm{P}=0.005)$ and $\mathrm{BPP}$ group 
Table 1 Clinical data of the four surgical groups

\begin{tabular}{|c|c|c|c|c|c|}
\hline Characteristics & $E S A(n=37)$ & $\operatorname{APP}(n=53)$ & $\operatorname{BPP}(n=20)$ & APAP $(n=11)$ & $P$ value \\
\hline Age at surgery (days) & $89.5(51.3-146.0)$ & $54.0(39.0-102.5)$ & $69.5(50.8-105.8)$ & $50.0(29.0-88.0)$ & 0.080 \\
\hline Neonates (\%) & $2(5.4)$ & $8(15.1)$ & $2(10.0)$ & $1(9.1)$ & 0.512 \\
\hline Weight at surgery (kg) & $4.6(3.8-5.6)$ & $4.2(3.5-5.0)$ & $4.2(3.5-4.9)$ & $3.8(3.6-4.6)$ & 0.268 \\
\hline \multicolumn{6}{|l|}{$\begin{array}{l}\text { Major associated cardiac } \\
\text { anomalies (\%) }\end{array}$} \\
\hline Ventricular septal defect & $31(83.8)$ & $39(73.6)$ & $15(75.0)$ & $9(81.8)$ & 0.682 \\
\hline Atrial septal defect & $17(45.9)$ & $31(58.5)$ & $14(70.0)$ & $7(63.6)$ & 0.325 \\
\hline Tricuspid valve regurgitation & $9(24.3)$ & $16(30.2)$ & $1(5.0)$ & $1(9.1)$ & 0.120 \\
\hline Pulmonary valve stenosis & $0(0.0)$ & $0(0.0)$ & $1(5.0)$ & $0(0.0)$ & 1.000 \\
\hline $\begin{array}{l}\text { Persistent left superior vena } \\
\text { cava }\end{array}$ & $3(8.1)$ & $4(7.5)$ & $4(20.0)$ & $0(0.0)$ & 0.324 \\
\hline Double outlet right ventricle & $0(0.0)$ & $1(1.9)$ & $0(0.0)$ & $0(0.0)$ & 1.000 \\
\hline Preoperative LVEF (\%) & $70.6(65.7-77.4)$ & $66.0(60.4-73.2)$ & $67.7(55.5-73.1)$ & $71.0(61.2-75.8)$ & 0.060 \\
\hline Preoperative LVFS (\%) & 38.5 (33.9-45.2) & $34.4(30.6-39.1)$ & $35.9(27.5-40.4)$ & $38.4(31.1-43.1)$ & 0.052 \\
\hline
\end{tabular}

ESA, end-to-side anastomosis; APP, autologous pericardial patch; BPP, bovine pericardial patch; APAP, autologous pulmonary artery patch; LVEF, left ventricular ejection fraction; LVFS, left ventricular fraction shortening.

$(\mathrm{P}<0.001)$. The BPP group showed a longer aortic crossclamp time than the APP group $(\mathrm{P}=0.022)$. Compared with the ESA and APAP groups, the BPP group demonstrated a longer cardiopulmonary bypass time. No differences were found in the postoperative pressure gradient, intensive care unit (ICU) stay, in-hospital time, or mechanical support time between the four groups (Table 2).

\section{Recoarctation}

Of the 121 patients, 44 developed recoarctation after the initial aortic arch reconstruction surgery. During the followup period, 19 infants $(51.4 \%)$ developed recoarctation in ESA group. In the patch group, 25 patients $(30.0 \%)$ developed recoarctation: $16(30.2 \%)$ in the APP group, $8(40.0 \%)$ in the BPP group and $1(9.1 \%)$ in the APAP group. The ESA group showed a higher recoarctation rate than the APAP group $(\mathrm{P}=0.013)$. Of the 44 recoarctation patients, 4 patients underwent second surgery via patch enlargement, 2 in the ESA group and 2 in the APP group. Overall, 8 patients underwent transcatheter balloon dilation and stenting: 3 in the ESA group, 2 in the APP group and 3 in the BPP group. The others were under conservative follow-up.

Figure 4 shows freedom from recoarctation in patients in whom different arch repair techniques were used, according to the Kaplan-Meier curve. Compared with the other groups, the ESA group demonstrated significantly higher recoarctation rates (Figure 5; $\mathrm{P}<0.05$, Mantel-Cox 
Table 2 Postoperative outcomes of the four surgical groups

\begin{tabular}{|c|c|c|c|c|c|}
\hline Characteristics & $\mathrm{ESA}(n=37)$ & APP $(n=53)$ & $\operatorname{BPP}(n=20)$ & APAP $(n=11)$ & $P$ value \\
\hline DHCA (\%) & $9(24.3)$ & $9(17.0)$ & $1(5.0)$ & $3(27.3)$ & 0.268 \\
\hline $\begin{array}{l}\text { Postoperative pressure } \\
\text { gradient }(\mathrm{mmHg})\end{array}$ & $15.7 \pm 3.6$ & $14.3 \pm 3.8$ & $14.7 \pm 3.87$ & $15.0 \pm 3.6$ & 0.434 \\
\hline ICU stay (h) & $135.8(94.3-170.1)$ & $159.9(120.0-192.0)$ & $138.4(106.1-174.2)$ & $144.0(120.0-163.7)$ & 0.296 \\
\hline Mechanical support time (h) & $65.1(43.0-106.0)$ & $98.4(56.8-121.1)$ & $71.6(37.2-127.7)$ & 64.9 (30.0-99.3) & 0.067 \\
\hline Recoarctation (\%) & $19(51.4)$ & $16(30.2)$ & $8(40.0)$ & $1(9.1)$ & $0.044^{*}$ \\
\hline Surgery & $2(10.5)$ & $2(12.5)$ & $0(0.0)$ & $0(0.0)$ & 0.839 \\
\hline $\begin{array}{l}\text { Transcatheter balloon } \\
\text { dilatation }\end{array}$ & $3(15.8)$ & $2(12.5)$ & $3(37.5)$ & $0(0.0)$ & 0.511 \\
\hline Conservative follow-up & $14(73.7)$ & $12(75.0)$ & $5(62.5)$ & $1(100.0)$ & 0.867 \\
\hline
\end{tabular}

*, P<0.05. ESA, end-to-side anastomosis; APP, autologous pericardial patch; BPP, bovine pericardial patch; APAP, autologous pulmonary artery patch; DHCA, deep hypothermic circulatory arrest; DHLF, deep hypothermic low flow; SACP, selective antegrade cerebral perfusion; ICU, intensive care unit.

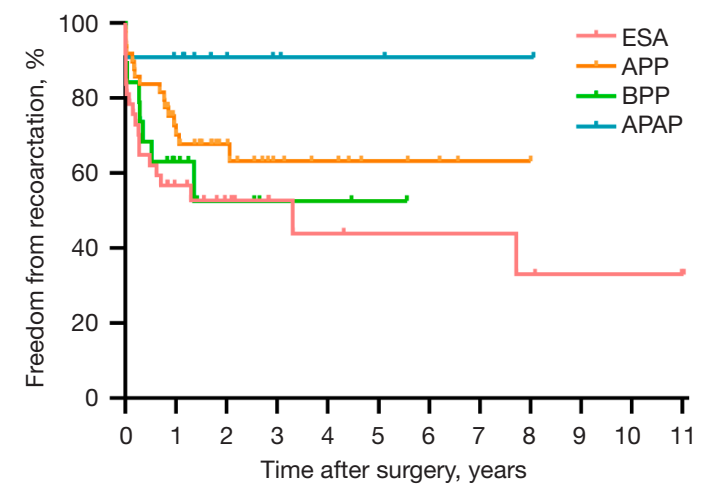

Figure 4 Kaplan-Meier analysis of freedom from recoarctation after the initial operation in the four surgical groups. ESA, end-toside anastomosis; APP, autologous pericardial patch; BPP, bovine pericardial patch; APAP, autologous pulmonary artery patch.

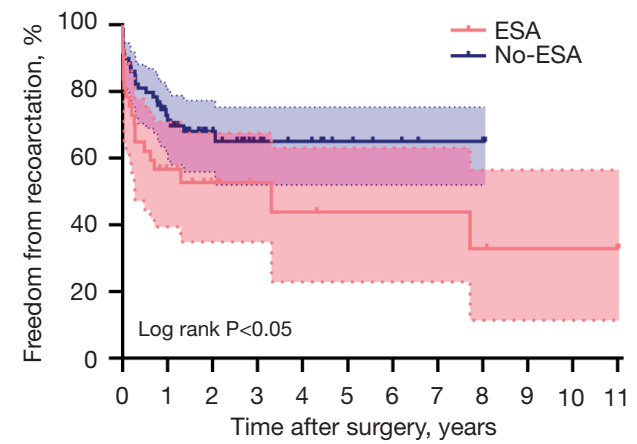

Number at risk

ESA $37 \begin{array}{lllllllllll}36 & 11 & 7 & 6 & 5 & 5 & 5 & 4 & 3 & 2 & 1\end{array}$ $\begin{array}{lllllllllllll}\text { No-ESA } & 84 & 47 & 26 & 15 & 12 & 8 & 5 & 3 & 3 & 0 & 0 & 0\end{array}$

Figure 5 Kaplan-Meier analysis of freedom from recoarctation after the initial operation in the two surgical option groups. ESA, end-to-side anastomosis; No-ESA, surgical techniques excluding end-to-side anastomosis. 
Table 3 Results of univariate and multiple analyses for recoarctation

\begin{tabular}{|c|c|c|c|c|c|c|}
\hline Variables & \multicolumn{3}{|c|}{ Univariate } & \multicolumn{3}{|c|}{ Multivariate } \\
\hline Weight at surgery & 0.75 & $0.58-0.98$ & $0.032^{*}$ & 0.89 & $0.62-1.28$ & 0.526 \\
\hline Age at surgery & 0.99 & $0.99-1.00$ & $0.021^{*}$ & 0.99 & $0.98-1.00$ & 0.081 \\
\hline Neonatal surgery & 2.83 & $1.35-5.93$ & $0.006^{*}$ & 1.89 & $0.80-4.46$ & 0.145 \\
\hline Preoperative LVFS (\%) & 1.00 & $0.96-1.03$ & 0.603 & & & \\
\hline Z-Score & 0.875 & $0.68-1.13$ & 0.310 & & & \\
\hline Cardiopulmonary bypass time & 1.00 & $1.00-1.01$ & 0.142 & & & \\
\hline Aortic cross-clamp time & 1.00 & $0.99-1.02$ & 0.700 & & & \\
\hline BPP & 1.25 & $0.58-2.70$ & 0.568 & & & \\
\hline APAP & 0.19 & $0.03-1.35$ & $0.097^{*}$ & 0.20 & $0.03-1.46$ & 0.111 \\
\hline
\end{tabular}

${ }^{*}, \mathrm{P}<0.1 ;{ }^{* *}, \mathrm{P}<0.05$. HR, hazard ratio; $\mathrm{Cl}$, confidence interval; LVEF, left ventricular ejection fraction; LVFS, left ventricular fraction shortening; ESA, end-to-side anastomosis; APP, autologous pericardial patch; BPP, bovine pericardial patch; APAP, autologous pulmonary artery patch.

log-rank test).

Cox regression univariate and multivariate analyses revealed that ESA [hazard ratio $(\mathrm{HR})=1.86 ; \mathrm{P}=0.043$ and $\mathrm{HR}=2.13 ; \mathrm{P}=0.020$, respectively] was an independent risk factor for recoarctation after PDTA repair (Table 3).

\section{Discussion}

In this study, of the 121 patients, 44 developed recoarctation after the initial aortic arch reconstruction surgery. During the follow-up period, 19 infants (51.4\%) developed recoarctation in the ESA group. In the patch group, 25 patients (30.0\%) developed recoarctation: $16(30.2 \%)$ in the APP group, $8(40.0 \%)$ in the BPP group and $1(9.1 \%)$ in the APAP group. We found that ESA showed a higher incidence of recoarctation after surgery than patch aortoplasty. Furthermore, the results demonstrated that ESA is an independent risk factor for recoarctation.

To prevent postoperative recoarctation, relief of anastomotic tension is the most crucial factor in the treatment of PDTA hypoplasia $(9,10)$. Aortic arch reconstruction can rarely be performed without tension in patients with long distances between the hypoplastic segment (11). If the early anastomotic tension is not treated well, late recoarctation could be inevitable in the future (9).

The other key point of transverse arch reconstruction is proximal arch treatment. It is still under debate whether the proximal arch should be treated. Some studies have shown variable degrees of growth potential in patients whose proximal arch was not treated $(12,13)$. However, inadequate growth potential of the proximal arch may lead to the late development of recurrent arch obstruction (2).

\section{Proximal arch bypoplasia}

Hypoplasia of the proximal arch is not simply a miniature segment of the normal aortic arch. The hypoplastic aorta has a relatively higher number of elastin lamellae and more collagen than the normal aortic arch, which could limit the hypoplastic segment distension. Furthermore, the differentiation phenomenon of the smooth muscle cells in the media wall has been considered the pathological mechanism of limited growth potential, which could lead to late recoarctation $(3,14)$. Because of the histologic changes of the hypoplastic segment, the hypoplastic proximal arch should be treated, and autologous tissue is preferred between the proximal and distal parts of the repair site. 


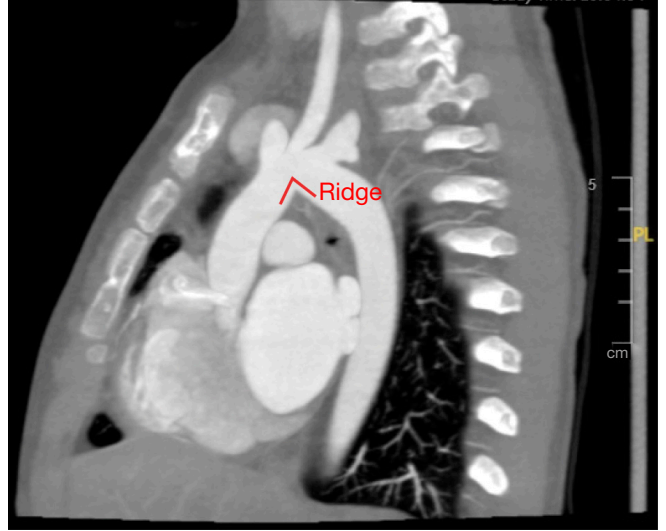

Figure 6 Formation of the anastomotic ridge postoperatively.

However, in our study, there were no significant differences in recoarctation rates among different patch materials.

\section{ESA}

It is controversial whether ESA should be performed in patients with PDTA hypoplasia. Some studies have revealed that ESA could be achieved with good and favorable outcomes $(15,16)$. However, another study found that compared with more extensive anastomosis, ESA has some pitfalls $(2,9)$. Additionally, our study showed that ESA has its shortcomings.

In our center experience, there are four explanations for the higher recoarctation incidence of ESA: neostenosis, geometry, aortopulmonary space, and growth potential. First, because of the ascending aortic cannulation and anastomotic ridge formation, neostenosis may account for postoperative proximal arch recoarctation. The use of a purse-string suture on the anterior aortic wall may give rise to suture-site invagination. Furthermore, direct anastomosis to the proximal arch decreases the length of the transverse arch and enables the facile formation of the anastomotic ridge, with no outward abnormal surgical appearance but in the radiographic finding (Figure 6). To prevent late neostenosis, the ascending aorta could be suspended during the initial procedure.

Second, although the distal descending aorta is widely mobilized, direct anastomosis may decrease the length of the transverse arch, which increases the ratio of the width of the aortic arch to its height (ratio A/T). An increased $\mathrm{A} / \mathrm{T}$ ratio is believed to be associated with late systemic hypertension after aortic reconstruction (17). Moreover, the differential growth between the proximal and distal aortas to the angulation side contributes to the late formation of the Gothic arch geometry and associated abnormal arch hemodynamics $(2,18)$.

Third, direct anastomosis could reduce the aortopulmonary space and even aggravate the compression of the right pulmonary artery or left main bronchus, especially in patients who need postoperative mechanical support.

Finally, considering the histological changes of the hypoplastic segment and previous study data, waiting for the growth potential of the proximal aortic arch may not be sufficient. In other words, despite the catch-up growth of the proximal aortic arch after the reconstruction surgery in a direct anastomosis group, the diameter of the proximal arch might not reach normal values $(2,14)$.

\section{Patch aortoplasty}

Recently, various patch materials have been utilized in aortic arch reconstruction $(2,11,19,20)$. Some scholars consider patch aortoplasty as the choice of treatment for recurrent obstruction (3). However, in our experience, the utilization boundary of the patch in arch reconstruction should be extended. Our results demonstrate that patch aortoplasty is a safe and effective choice for aortic arch reconstruction, with a low incidence of recoarctation.

In patch aortoplasty, anastomotic tension and arch geometry can be considered. Patch repair can sufficiently enlarge the hypoplastic segment to prevent the presence of recoarctation and maintain a relatively normal geometry $(9,21)$. Compared with the ESA group, the patch repair groups tended to show a longer cardiopulmonary bypass time and aortic cross-clamp time. However, our outcomes showed that the ICU stay, mechanical support time, and inhospital time were not significantly different between the four groups.

Additionally, considering the growth potential of the aortic arch, the autologous artery patch would be beneficial for the growth of the entire aortic arch. The pulmonary artery is homogeneous to the transverse aortic arch, which not only maintains the aorta elastic ability, but also has the potential to grow with aging $(20,22)$. In our follow-up cohort, only 1 of 11 patients in the APAP group developed recoarctation. Nevertheless, the additional surgical procedure may prolong the operative time, and the patch material may be limited by the length and width of the pulmonary artery. Furthermore, this approach potentially causes antigenicity of the patch and alteration of the 
contour of the aortic arch (11).

To prevent the prevalence of aneurysm or recoarctation, the design and trim of the patch are controversial issues. To understand the entire anastomotic geometry during surgery, we could release the distal aortic clamp and then design a patch with the proper shape. Compared with the preoperative patch design, this procedure was more reasonable and close to the actual condition. For the autologous pulmonary patch, in our center experience, a piece of oval anterior wall of the MPA to the beginning of the left pulmonary artery was harvested.

\section{Limitations}

This study has some limitations. First, it was a single-center retrospective comparative study; thus, its findings need to be proven through prospective comparative studies at multiple centers. Second, according to our collected data, EAAA was performed in only seven patients. Because of the limited number of patients, these seven patients were not included in this analysis. Third, institutional bias, surgeon experience, and surgeon preferences were another limitations of this study. Fourth, some data including blood pressure or abdominal aorta pulse were not routine recorded during follow-up examination. Further studies involving other surgical techniques, such as EAAA, longer follow-up time and multiple center data are warranted.

\section{Conclusions}

Our study demonstrated that aortic arch reconstruction via ESA in patients with PDTA hypoplasia was an independent risk factor for recoarctation. In our experience, some pitfalls were associated with ESA, including neostenosis, Gothic arch geometry potential, underlying compression of the right pulmonary artery or left main bronchus, and inadequate growth potential.

Additionally, the indications for using patches in arch reconstruction should be expanded. Intraoperatively, if mobilization of the descending aorta is limited or the aortic arch geometry appears abnormal, patch aortoplasty should be chosen to reconstruct the aortic arch.

\section{Acknowledgments}

Funding: This work was supported by Shanghai Science and Technology Committee (grant number 1941196490) and
Shanghai Municipal Health Commission (grant number 20194Y0301).

\section{Footnote}

Reporting Checklist: The authors have completed the STROBE reporting checklist. Available at https:// tp.amegroups.com/article/view/10.21037/tp-21-557/rc

Data Sharing Statement: Available at https://tp.amegroups. com/article/view/10.21037/tp-21-557/dss

Conflicts of Interest: All authors have completed the ICMJE uniform disclosure form (available at https://tp.amegroups. com/article/view/10.21037/tp-21-557/coif). The authors have no conflicts of interest to declare.

Ethical Statement: The authors are accountable for all aspects of the work in ensuring that questions related to the accuracy or integrity of any part of the work are appropriately investigated and resolved. The study was conducted in accordance with the principles of the Declaration of Helsinki (as revised in 2013) and approved by the Ethics Committee of Shanghai Children's Medical Center (No. SCMCIRB-W2021038). The requirement for obtaining individual consent for this retrospective analysis was waived. This study has been registered with the Chinese Clinical Trials Registry (https://www.chictr.org.cn) as ChiCTR2100048212.

Open Access Statement: This is an Open Access article distributed in accordance with the Creative Commons Attribution-NonCommercial-NoDerivs 4.0 International License (CC BY-NC-ND 4.0), which permits the noncommercial replication and distribution of the article with the strict proviso that no changes or edits are made and the original work is properly cited (including links to both the formal publication through the relevant DOI and the license). See: https://creativecommons.org/licenses/by-nc-nd/4.0/.

\section{References}

1. Poncelet AJ, Henkens A, Sluysmans T, et al. Distal Aortic Arch Hypoplasia and Coarctation Repair: A Tailored Enlargement Technique. World J Pediatr Congenit Heart Surg 2018;9:496-503.

2. Murtuza B, Alsoufi B. Current Readings on Surgery for 
the Neonate With Hypoplastic Aortic Arch. Semin Thorac Cardiovasc Surg 2017. [Epub ahead of print]. doi: 10.1053/ j.semtcvs.2017.11.004.

3. Brown JW, Rodefeld MD, Ruzmetov M. Transverse aortic arch obstruction: when to go from the front. Semin Thorac Cardiovasc Surg Pediatr Card Surg Annu 2009;66-9.

4. Walhout RJ, Lekkerkerker JC, Oron GH, et al. Comparison of polytetrafluoroethylene patch aortoplasty and end-to-end anastomosis for coarctation of the aorta. J Thorac Cardiovasc Surg 2003;126:521-8.

5. Tsang V, Haapanen H, Neijenhuis R. Aortic Coarctation/ Arch Hypoplasia Repair: How Small Is Too Small. Semin Thorac Cardiovasc Surg Pediatr Card Surg Annu 2019;22:10-3.

6. Zannini L, Gargiulo G, Albanese SB, et al. Aortic coarctation with hypoplastic arch in neonates: a spectrum of anatomic lesions requiring different surgical options. Ann Thorac Surg 1993;56:288-94.

7. Pettersen MD, Du W, Skeens ME, et al. Regression equations for calculation of $\mathrm{z}$ scores of cardiac structures in a large cohort of healthy infants, children, and adolescents: an echocardiographic study. J Am Soc Echocardiogr 2008;21:922-34.

8. Turek JW, Conway BD, Cavanaugh NB, et al. Bovine arch anatomy influences recoarctation rates in the era of the extended end-to-end anastomosis. J Thorac Cardiovasc Surg 2018;155:1178-83.

9. Rakhra SS, Lee M, Iyengar AJ, et al. Poor outcomes after surgery for coarctation repair with hypoplastic arch warrants more extensive initial surgery and close long-term follow-up. Interact Cardiovasc Thorac Surg 2013;16:31-6.

10. Mery CM, Guzmán-Pruneda FA, Carberry KE, et al. Aortic arch advancement for aortic coarctation and hypoplastic aortic arch in neonates and infants. Ann Thorac Surg 2014;98:625-33; discussion 633.

11. Gray WH, Wells WJ, Starnes VA, et al. Arch Augmentation via Median Sternotomy for Coarctation of Aorta With Proximal Arch Hypoplasia. Ann Thorac Surg 2018;106:1214-9.

Cite this article as: Li C, Ma J, Yan Y, Chen H, Shi G, Chen H, Zhu Z. Surgical options for proximal and distal transverse arch hypoplasia in infants with coarctation. Transl Pediatr 2022;11(3):330-339. doi: 10.21037/tp-21-557
12. Siewers RD, Ettedgui J, Pahl E, et al. Coarctation and hypoplasia of the aortic arch: will the arch grow? Ann Thorac Surg 1991;52:608-13; discussion 613-4.

13. Liu JY, Kowalski R, Jones B, et al. Moderately hypoplastic arches: do they reliably grow into adulthood after conventional coarctation repair? Interact Cardiovasc Thorac Surg 2010;10:582-6.

14. Machii M, Becker AE. Hypoplastic aortic arch morphology pertinent to growth after surgical correction of aortic coarctation. Ann Thorac Surg 1997;64:516-20.

15. Dharmapuram AK, Ramadoss N, Verma S, et al. Early outcomes of modification of end to side repair of coarctation of aorta with arch hypoplasia in neonates and infants. Ann Pediatr Cardiol 2018;11:267-74.

16. Liu JY, Jones B, Cheung MM, et al. Favourable anatomy after end-to-side repair of interrupted aortic arch. Heart Lung Circ 2014;23:256-64.

17. Ou P, Bonnet D, Auriacombe L, et al. Late systemic hypertension and aortic arch geometry after successful repair of coarctation of the aorta. Eur Heart J 2004;25:1853-9.

18. Tulzer A, Mair R, Kreuzer M, et al. Outcome of aortic arch reconstruction in infants with coarctation: Importance of operative approach. J Thorac Cardiovasc Surg 2016;152:1506-13.e1.

19. Bernabei M, Margaryan R, Arcieri L, et al. Aortic arch reconstruction in newborns with an autologous pericardial patch: contemporary results. Interact Cardiovasc Thorac Surg 2013;16:282-5.

20. Wen S, Cen J, Chen J, et al. The application of autologous pulmonary artery in surgical correction of complicated aortic arch anomaly. J Thorac Dis 2016;8:3301-6.

21. Seo DM, Park J, Goo HW, et al. Surgical modification for preventing a gothic arch after aortic arch repair without the use of foreign material. Interact Cardiovasc Thorac Surg 2015;20:504-9.

22. Ma ZL, Yan J, Li SJ, et al. Coarctation of the Aorta with Aortic Arch Hypoplasia: Midterm Outcomes of Aortic Arch Reconstruction with Autologous Pulmonary Artery Patch. Chin Med J (Engl) 2017;130:2802-7. 